\title{
Carbon Trading: A Study of Trends and Evolution
}

\author{
K.V. Bhanu Murthy* and Sakshi Gambhir**
}

\begin{abstract}
The global energy landscape is rapidly changing as a result of economic shifts and technological breakthroughs. There has been an increased focus on climate change through the phenomenon of global warming, which is caused by accumulation of green house gases $(G H G)$ in the atmosphere. Efforts have been underway at the international as well as national level for abatement of GHG emissions through cost-effective and sustainable solutions. The UNFCCC with its mandate of a safer future launched the Kyoto Protocol in 1997, to firm-up ongoing efforts for stabilizing the ecosystems. The Protocol commits its Parties through internationally binding emission reduction commitments. The idea was to create an international unified carbon market, which would render a check on the worldwide emission levels. However, actual experience with the markets has revealed that the dream of a global top-down market is far from being realised. Against this backdrop, this paper attempts to review the evolution of carbon markets, through the mechanism of International Emissions Trading. It also highlights some trends and developments that have characterised these markets over the past few years. Overall, the literature seems to signify the emergence of a decentralised bottom-up design of the market. There is a multitude of regional, national and subnational markets in operation, with EU ETS as the frontrunner. Moreover, these systems are starting to link with one another to facilitate the evolution of an international carbon market, in the wake of an unpromising future outlook for Kyoto credits.
\end{abstract}

Keywords: Carbon trading, Greenhouse gases, Kyoto Protocol.

\subsection{Introduction}

The debate on growth and development has largely been argued during the seventies and eighties the world over. There were two identifiable strategies of economic development mainly meant for developing economies, namely the import substitution strategy and the export-oriented strategy.

\footnotetext{
*Professor, Department of Commerce, Delhi School of Economics, University of Delhi

**Assistant Professor, Hansraj College, University of Delhi.
} 
With the advent of newly industrialised economies and particularly the four 'Tigers of Asia', the development model was nearly identified as an open economy model. Hence, any debate on development had to necessarily incorporate trade as an essential dimension of strategies for economic development. Thus, growth or development strategies are normally referred to as "Trade and Development Strategies". Subsequent to the eighties, in the nineties the concern shifted towards the global environment through the emphasis on pollution and other forms of environmental degradation. This awareness came about following the sudden rise in environmental variables, particularly carbon dioxide $\left(\mathrm{CO}_{2}\right)$ emissions. The awareness has been further strengthened by global phenomenon such as global warming, which is caused by accumulation of greenhouse gases (GHG), mainly $\mathrm{CO}_{2}$ in the atmosphere. So, in recent times, it has dawned upon the world at large that the overarching issue is the environment, which has resulted in the entire development debate being revisited from the point of view of trade, development and the environment.

Against this backdrop, The United Nations Framework Convention on Climate Change (UNFCCC) proposed the Kyoto protocol in 1997, which commits its Parties through internationally binding emission reduction commitments. The Protocol was adopted on 11 December 1997 in Kyoto, Japan and came into force on 16 February 2005. Its first commitment period started in 2008 and ended in 2012. The second commitment period from 2013 to 2020 has Parties committing to reduce GHG emissions by at least 18 percent below 1990 levels. The composition of Parties however, in the second period differs from the first.

International emissions (or carbon) trading was one of the mechanisms introduced to facilitate countries in complying with the targets prescribed by the Protocol. These targets are expressed as levels of allowed emissions, which are divided into "assigned amount units" (AAUs), each equal to one ton of $\mathrm{CO}_{2}$. Emissions' trading allows countries with $\mathrm{CO}_{2}$ emissions above prescribed quota (by the protocol) to purchase the right to release more $\mathrm{CO}_{2}$ in the atmosphere from countries with emissions below quota. Thus, one ton of $\mathrm{CO}_{2}$ or a corresponding amount of some other greenhouse gas could be discharged in the atmosphere through what came to be known as 'carbon credits' (Gupta, 2011).Countries with excess emissions must buy credits while those below, could sell remaining credits. These credits could be exchanged between businesses or bought and sold in international markets at prevailing market prices.

Hence, carbon is now being tracked and traded like any other commodity. This has led to creation of the 'carbon market'. The idea is to keep the worldwide carbon emissions within permissible levels and at the same time provide firms with a financial incentive to pollute less. 
The rest of the paper is organised as follows. Section 2 lays down the conceptual framework for emissions trading. Section 3 discusses the policy framework. Section 4 provides a brief review of some studies on carbon trading. Section 5 discusses some key trends and developments in carbon markets. Section 6 concludes.

\subsection{Conceptual Framework}

The UNFCCC came into force in 1994 with the ultimate aim of preventing dangerous human induced intrusion in the climate system. In the wake of soaring GHG concentrations in the atmosphere, efforts directed at stabilising the ecosystems seemed rather imperative. The idea was to enable the bionetworks to naturally adapt to climate change and proceed towards economic development in a sustainable manner.

The Kyoto Protocol operationalised the Convention, by committing 37 industrialised countries and the European community in its first commitment period (2008 to 2012) to bring about an average 5 per cent emissions reduction compared to 1990 levels. In Doha, Qatar, on 8 December 2012, the Doha Amendment to Kyoto Protocol was adopted, launching a second commitment period from 1 January 2013 to 31 December 2020, with Parties committing to reduce GHG emissions by at least 18 percent below 1990 levels. The composition of Parties however, in the two commitment periods varies.

To enable Parties to meet their emission reduction targets, the Protocol offers three market-based mechanisms, namely International Emissions Trading, the Clean Development Mechanism (CDM) and Joint Implementation (JI). The CDM permits Parties to the Protocol to implement emission reduction projects in developing countries. Such projects enable Parties to earn Certified Emission Reduction (CER) credits, each equal to one ton of carbon dioxide. CERs can be traded, sold and used by Parties to meet their emission reduction targets as set by the Protocol. Moreover, JI allows Parties to earn Emission Reduction Units (ERUs), each equal to one ton of $\mathrm{CO}_{2}$, by undertaking emission reduction or emission removal projects in another country that is party to the Protocol. The ERUs are converted from AAUs and issued by the host country of the project.

Therefore, the units that are traded in the carbon markets may be in the form of AAUs, ERUs, CERs and/or RMUs. Parties could issue a RMU (removal unit) on the basis of land use, land-use change and forestry (LULUCF) activities such as reforestation. Moreover, emissions trading schemes could be established at the regional, national or sub-national levels. Under such schemes, governments set emission reduction 
obligations to be met by the participants. The European Union Emissions Trading System (EU ETS) is the largest such scheme in operation.

The UNFCCC monitors emission targets through its Registry Systems, which track and record transactions by Parties under the Kyoto mechanisms. Countries submit annual emission inventories and national reports at regular intervals and they are assisted in complying with the targets, if required.

The Kyoto Protocol places a heavier burden on developed nations emphasising their responsibility for the current high levels of GHG emissions in the atmosphere, but through its market-based mechanisms incites GHG diminution to start where it is most cost-effective, such as in the developing world. This would not only bring down emissions in the atmosphere but also stimulate green investments in developing countries and include the private sector in endeavours of stabilising the ecosystems.

Thus, the Protocol has inspired governments to formulate policies and enforce legislations to meet their respective emission reduction commitments. It has also urged businesses to make environment-friendly investment decisions and mostly, enabled the creation of a carbon market.

\subsection{Policy Framework}

Energy-related $\mathrm{CO}_{2}$ emissions are the majority of global greenhouse gas emissions. The fight against climate change has become a defining feature in energy policy-making, but the implications are daunting. According to International Energy Agency estimates, meeting the emission goals pledged by countries under the UNFCCC would still leave the world with 13.7 billion tons of $\mathrm{CO}_{2}-$ or $60 \%$ - above the level needed to remain on track for just $2^{\circ} \mathrm{C}$ warming by 2035 .

Emissions could be lowered in two ways - on the supply side and on the demand side. For instance, on the supply side, it can be done by switching from electricity generation from fossil fuels to renewable sources, or deploying carbon capture and storage. On the demand side, emissions could be lowered by reduction of energy intensity of end-use technologies or by reduction of demand for energy and transport services.

Governments may choose from a range of policy instruments while designing national energy policies and complement national efforts for emissions reductions with international cooperation mechanisms. At the national level, governments may ascribe authorities to design projects for abatement or intervene through instruments. There are a variety of instruments through which governments could intervene. On one hand, standards, bans or licenses could be used to induce the use of environment-friendly 
technologies, products or appliances; on the other, economic instruments such as taxes, subsidies or tradable emissions permits could be considered. Further, emission taxes could be set either in the form of carbon taxes or taxes may be laid down on fossil fuels; that is, products need to be differentiated based on the carbon content of the fuel. For end users, energy taxes could be imposed for increased consumption of heat and electricity. Moreover, subsidies could take the form of low interest rate loans or tax allowances to support transition to new technologies. Also, rendering awareness on opportunities for reduction of energy consumption could make a further dent on the demand side. In addition, agreements could be negotiated, where targets are agreed between firms and authorities to facilitate reduction on both demand and supply sides (Dinica, 2002).

The choice among policy instruments would depend on a lot factors such as their likely environmental effectiveness or cost efficiency. Standards would be environmentally effective but not cost efficient, while taxes would be cost-efficient but less effective than standards. Emissions trading mechanisms, on the other hand, would not only be environmentally effective and cost-efficient but also encourage innovation, as firms would be in search for cheaper and new technology options to bring about a reduction in emissions and improve their position in the market.

However, the cost-efficiency of emissions trading could be impaired by high transaction costs. Reduction in the scale of markets could subside this shortcoming but in order to keep the innovation rate at high levels in the long term, increase in market size would be necessary, which would increase the transaction costs. Furthermore, if international emissions' trading is permitted, some incongruities might emerge with regard to application of standards or taxes at national levels for actors involved in international trade, unless these standards or taxes are internationally harmonized (Dinica, 2002). Overall, the composition and strength of energy policies for GHG abatement would strongly depend on targets for emissions reduction, which would require constant modifications in the light of forecasts for economic growth and population.

\subsection{Literature Review}

This section reviews the extant literature on the understanding, working and effectiveness of carbon trading mechanisms. Gupta (2011) provides a basic understanding of the concept of Carbon Trading and its importance, in the backdrop of growing concerns about the environment. She further throws light on the methods used to save the environment and also presents the case for emergence of India as a key player in the global carbon credits market. Trading in carbon credits enables nations to meet 
their binding emission reduction commitments under the Kyoto Protocol, an initiative of The United Nations Framework Convention on Climate Change (UNFCCC). This system allows countries with $\mathrm{CO}_{2}$ emissions above prescribed quota to purchase the right to release more $\mathrm{CO}_{2}$ in the atmosphere from those with emissions below quota. The researcher emphasises that India has below target GHG emissions, entitling it to sell surplus credits to developed countries. This, when considered with its $31 \%$ share in world carbon trade, could offer a great business opportunity. The Indian farming community, businesses in wind energy, the DMRC (Delhi Metro Rail Corporation) and companies registering for CDM (Clean Development Mechanism) projects were some entities expected to benefit. Hence, fostering greater awareness about carbon trading among corporates could enable India's emergence as a key player in the global emissions market.

Further, attempting to offer solutions for global warming, Gupta (2011) discusses the concept of carbon offset, an instrument equivalent to reduction of one metric ton of $\mathrm{CO}_{2}$ in the atmosphere. Individuals and corporates by buying such offsets could promote cleaner and renewable energy sources and also fund conservation and reforestation projects. To add to this, efforts on an individual level such as switching off the lights when not required, use of low-energy bulbs and renewable fuels, tree plantation and carpooling, were stressed to prevent further environmental damage. It is concluded, that though there is dearth of awareness about the intricacies of carbon markets, the ease and simplicity associated with carbon trading had been furthering demand for the same and with new financial instruments entering the markets, this system was expected to become more popular and successful in future. India, through innovative strategies, could be expected to occupy a special place and lead other developing countries in the arena of carbon trading.

Newell et al. (2013) examine the post Kyoto Protocol scenario with respect to global carbon trading in order to highlight the lessons learned and challenges brought forward by the same. The analysis focuses on critical assessment of five arenas constituting the vast majority of carbon markets around the world as of the end of 2012. The arenas reviewed are: The European Union's Emissions Trading System (ETS); the Clean Development Mechanism (developed under the Kyoto Protocol); the Regional Greenhouse Gas Initiative (northeastern United States); New Zealand's Emissions Trading Scheme; and voluntary markets including those emerging in California, Australia and few others.

The findings suggest that the dream of a single global carbon market as envisaged under the Kyoto Protocol seemed a far-fetched one as a multitude of regional, national and even sub-national markets have emerged. With actual experience from these 
markets some key lessons were learned regarding, the extent of emissions reduction achieved, inspiration induced for long term investments in low carbon technologies, distributional and efficiency consequences of allowance allocation, risk of emissions leakage to unregulated jurisdictions, high or volatile allowance prices, flexibility rendered through banking and borrowing of allowances, role of offsets in reducing emissions in unregulated sources and the importance of government oversight in the carbon markets.

Moreover, the growth of multiple carbon trading programs brought to the fore some key challenges with respect to linkage of separate emission trading systems, revision of government set out rules, diversity in abatement tools being contemplated by nations, institutional support for markets, need for market sensitivity in decision making and furtherance of the emerging bottom up approach in global carbon trading. The researcher concluded that though the prospects of a top-down global design of carbon markets as set out under the Kyoto Protocol were limited, it was clear that carbon markets were a reality in bringing down carbon emissions and sending market signals for future investments.

Branger et al. (2013) review the effectiveness of The European Union Emissions Trading System (EU-ETS) in bringing about real abatements against the backdrop of its many criticisms from different stakeholders. In particular, the following concerns are reviewed: inadequate carbon emissions reduction, carbon leakage and competitiveness issues, unfair distributional effects, nature of fraudulent activities and the existence of overlapping climate policy instruments. The findings suggest that the EU-ETS led to effective though small mitigation and its ability in encouraging long-term investments in low carbon technologies was only limited. The environmental efficiency of the system could be enhanced however, by completely banning foreign offsets. Further, the competitiveness losses and carbon leakage as argued did not seem to have occurred. But the distributional effects had been indeed unfair, as prices of allowances were passed on to the end users resulting in significant windfall profits for sectors receiving free allowances. However, such experiences had resulted in the Commission switching to auctioned allocations post 2013 though only for the electricity sector. To add to this, the system had witnessed noteworthy fraud on account of Value Added Tax (VAT), identity thefts by cyber-attacks and recycling of Certified Emission Reduction (CER) offset credits remitted by the Hungarian administration. Lastly, there wasn't enough evidence to condemn other climate policies covering the EU-ETS sectors. In fact, the presence of these policies was needed to ensure that the climate regime in EU would not be reduced to short-term fuel switching and energy conservation. 
The researchers concluded that majority of concerns raised with respect to EU-ETS were real, suggesting preference for an alternate climate policy such as a carbon tax. Though, some of the system's problems, in particular the unfair distribution effects, were initially inevitable, but others were clearly avoidable and even rectifiable based on review of system's flexibility mechanisms. To this end, regulation of carbon prices by setting a price ceiling and price floor during allowance auctions was suggested, which the commission had been hesitant to adopt because of highly ideological propositions. Political will and adherence to economists' recommendations were also propagated to tackle problems and eventually progress towards a price instrument.

Brandi (2013) examines the Border Carbon Adjustment measures from a normative perspective focusing on the dimensions of development ethics and environmental ethics in order to assess the impact of such measures on the lower-income developing countries. The database included absolute and relative trade flows in US dollars in the energy intensive sectors from low-income (LICs) and lower-middle income (LMICs) countries to the EU and US markets during the period 2004 to 2008. The sectors included in the analysis namely, iron and steel, aluminium, cement, glass, paper, clay and certain chemicals, were relevant both from the EU and the US context. Their findings suggest that from a development perspective, border carbon adjustments induced concerns. First, they hurt lower-income economies, especially the ones most vulnerable, because of concentration of their exports in a small number of sectors. They gathered that the most vulnerable LICs were Mozambique and Tajikistan in the EU market and Tajikistan and Zimbabwe in the US market. As far as LMICs were concerned, Ukraine was the most vulnerable with respect to US while Armenia, Ukraine, Moldova, Egypt, Jordan and Georgia were the most vulnerable ones with respect to EU. Second, border carbon adjustments limited market access for developing countries and thus, weakened the potential of trade to support development and reduce poverty.

From an environmental perspective too, border carbon adjustments seemed objectionable. Firstly, they allowed reservation of rights to unilaterally change the burden-sharing deal that would be agreed at the international level for a future postKyoto agreement. This would amount to distributive and procedural injustice. Secondly, they focused on the place of emission production and not consumption, and hence charged producers for relevant emissions and not those who demanded, imported and consumed goods encompassing those emissions. Thirdly, they burdened countries like Zimbabwe and others that had hardly had any historic responsibility for the current high levels of greenhouse gases in the atmosphere. The researcher concludes that attempts of bringing strong developing countries under the purview of border carbon adjustments would leave the relatively weaker ones exposed and vulnerable. Though the threat of 
such adjustments pushed certain emerging economies to adopt more stringent policies but such threats alone did not bring countries like China to the negotiations table, making international cooperation towards stabilizing greenhouse gas emissions even more difficult.

Against this backdrop, it was asserted that border carbon adjustments were found to be supportive of the central concerns of development and climate policy only if they assisted in reaching a global climate agreement. It was suggested that a legally binding agreement with full coverage and participation be fortified giving the developing countries a reasonable time frame to comply with. Also, an independent international body should be constituted to ensure consistency in climate legislations across nations, encourage usage of proceeds from border measures for affected lower-income countries and facilitate export diversification for the vulnerable ones. Overall, the consideration of human development and environmental ethics in deliberations on border carbon adjustments could foster international cooperation in pursuing greenhouse gases' emissions reduction.

Goldar and Pratap (2013) investigate the impact of binding commitments for reduction in $\mathrm{CO}_{2}$ emissions on the economies of India and China. The analysis was undertaken through counter-factual simulations for the year 2001 by developing scenarios in which India and China cut $\mathrm{CO}_{2}$ emissions by a specified percentage and there existed international trading in carbon. The study was based on a multi-country CGE framework. A modified version of the Global Trade Analysis Package (GTAP) model and database called GTAP-E model were used. Specifically, eight broad sectors (agriculture, coal mining, crude oil, natural gas extraction, refined oil products, electricity, energy insensitive industries and other industries and services) and three levels of emission cuts: 5, 10 and 15 percent, were considered for both countries.

Their findings suggest that there was no change in China's welfare for a 5 percent cut in emissions but a 10 percent and 15 percent cut reduced welfare by about 0.1 percent and 0.2 percent respectively. As far as India was concerned, a 5 and 10 percent cut in emissions increased welfare by 0.1 percent each, however a 15 percent cut had no impact on welfare. Moreover, a sector level analysis suggested that the output of energy intensive industries and coal fell by about 1.2 percent and 13 percent respectively in case of China. For India, such fall was about 0.6 percent and 23 percent respectively. Nevertheless, the percentage change (fall) in energy sector output was far larger than the change in the agriculture, energy intensive industries and other industries and services sector, for both the countries. This implied that reduction in emissions was being achieved primarily through substitution of energy by non-energy inputs. 
Further, the results from simulation (one where trading among India, China and Parties to the UNFCCC was allowed, called block carbon trading and the other, where trading among all countries was allowed, called global carbon trading) indicated that emission cuts of 10 percent and 15 percent reduced welfare both under block carbon trading and global carbon trading for China. For India, on the other hand, there was an increase in welfare by about 0.2 to 0.3 percent for similar emission cuts. In terms of marginal cost of reduction in emissions, both India and China gained under block carbon trading whereas under a global carbon trade scenario, welfare gains to India fell while welfare loss to China accentuated. Detailed sector wise estimation for 5, 10 and 15 percent emission cuts in the presence of global carbon trade in all the cases, revealed that, the higher the obligation for emissions cut, the higher was the fall in energy use, as testified by the electricity sector output and the domestic natural gas production. Moreover, fall in the net availability of crude oil and coal suggested an overall fall in the availability and use of energy inputs. Thus, replacement of domestic production of energy intensity products by imports could enable the demand for energy to be curbed.

It was concluded, that emissions cuts on the part of both India and China under scenarios of block carbon trade or global carbon trade, were far larger than the levels imposed on them. Existence of profitable carbon trading opportunities brought about as much as 20 percent cut in emissions against the imposed level of say, 5 percent, which encouraged these countries to go for cutting emissions voluntarily. Even, Parties to the UNFCCC benefited in terms of reduction in costs of meeting the required emission cuts. Consequently, the need for developing international markets for carbon trading was emphasized, besides enforcement of legally binding commitments for emissions reduction.

Lo (2013) captures the key features of the political economy of carbon trading in China and its likely implications for the global carbon market. The analysis pointed out two key features. Firstly, China's motivation behind establishing trans-provincial and trans-regional ETSs (Emission Trading Schemes) with eventual transition to a national scheme by 2015 was expected economic benefits rather than environmental commitments. Carbon trading promised efficiency and benefits from carbon finance, which supported China's top priority of unhindered economic development. Hence, the country saw carbon trading as an economic policy capable of delivering some environmental benefits instead of a purely environmental one. Secondly, the political realities of environmental governance in China, such as an extended regime of regulations and excessive state intervention were expected to challenge the theory of emissions trading. Political control over carbon prices under the prospective ETS was expected to result in price determination on the basis of political judgment rather than 
marginal cost of production. This managed carbon price would effectively become a kind of a carbon tax in co-existence with a carbon trading regime, in which both the prices and quantity of emissions would be governed by the state. This far from ideal state of the Chinese energy market coupled with the considerable economic implications of greenhouse gases control would subject the theory of carbon trading to an unusual test.

Lo (2013) concludes that carbon trading in China could make a notable difference to the global carbon market, as China's ETS initiatives were possibly the biggest test ever for the theory of carbon trading. Although, positive environmental outcomes and economic benefits were not mutually exclusive but the fundamentally different politicaleconomic scenario in China reduced the likelihood of an efficient outcome. However, the success or failure of this initiative and its comparison with the existing emission trading regimes, could prove to be crucial in understanding the ways in which the parameters of a political economy influenced construction of a market and whether existence of a liberal and democratic regime were necessary for producing environmental benefits.

\subsection{Carbon Markets: Trends and Developments}

Considering the magnitude of and urgency imposed by the menace of global warming, emission trading schemes are now increasingly appearing on the political agenda across the globe. Many countries have adopted Emission trading systems or have plans to do so in the coming years. Also, different systems are starting to link with one another, to enable achievement of emission reductions in the most cost effective way. According to World Bank (2014), about 40 national and 20 sub-national jurisdictions are now putting a price on carbon, and together they cover almost 6 giga tons of carbon dioxide equivalent $\left(\mathrm{GtCO}_{2} \mathrm{e}\right)$. Though the international scenario seems uncertain, progress at regional, national and sub-national levels continues to show some promise. Some developments worth mentioning include:

\subsection{Increasing reach}

Eight new carbon markets opened their doors in 2013 alone. These include systems in California, Quebec, Kazakhstan and five Chinese pilot emissions trading schemes. Apart from these, systems already in place include EU ETS, New Zealand, RGGI (US), California (US), Tokyo (JP), Switzerland, and South Korea to name a few. Moreover, Brazil, Chile, Ukraine, Thailand, Washington (US) are some of the emissions trading schemes under consideration. China now houses the second largest carbon market in the world, covering 1,115 megatons of carbon dioxide equivalent $\left(\mathrm{MtCO}_{2} \mathrm{e}\right)$, after the EU 
ETS with its 2,084 $\mathrm{MtCO}_{2} \mathrm{e}$ cap in 2013. Carbon taxes are also gaining ground.

\subsection{Demand and Supply Outlook for Credits}

Demand: Many players including financial institutions and private sector intermediaries have either exited the market or substantially reduced their activities. Moreover, major emitters such as Japan, New Zealand and Russia have officially withdrawn from the second commitment period of the Kyoto protocol. This, in addition to the bleak chances of recovery exhibited by the markets, has depressed the already limited demand. The maximum residual demand is estimated at around 1,120 to 1,230 megatons of carbon dioxide equivalent $\left(\mathrm{MtCO}_{2} \mathrm{e}\right)$, coming mostly from the EU ETS markets. But in the wake of current low prices, it is expected that EU ETS would exhaust most of its remaining credit limit in the next couple of years. This would leave Kyoto credits without their largest historic buyers.

Supply: The current CDM and JI portfolio is estimated to have the potential to issue between 3,500 and 5,400 $\mathrm{MtCO}_{2} \mathrm{e}$ for 2014-2020, should the demand exist. This is around three to five times the expected residual demand. Various initiatives underway might create additional demand for credits such as the Chinese pilot emissions trading schemes or the new Mexican tax but the impact of these initiatives is not likely to be enough to bridge the supply-demand gap and revive the market.

\subsection{Price signals}

Without the demand from EU ETS, Kyoto credit prices reached their historic lows in 2013 and 2014, with Certified Emission Reductions (CERs) worth just US\$0.51 (€0.37). Moreover, considering the disparity between demand for Kyoto credits between now and 2020 and the present range of projects for credits generation, the chances for retrieval seem rather bleak. Further, prices in emissions trading schemes also tend to be lower, clustering under US\$12/tCO $\mathrm{CO}_{2}$. The main reason for lower prices seem to be the exemptions offered to the industry and the consequent tax burden on private households, thereby ignoring the issues of competitiveness and carbon leakage. The Tokyo Cap-andTrade Program, on the other hand, exhibits a higher price at $\mathrm{US} \$ 12 / \mathrm{tCO}_{2}$, explained by an illiquid market where few permits are traded. On the whole, the price signals are diverse and do not seem reflective of a mature market.

\subsection{Overview of EU ETS: The largest Emissions Trading System in operation}

In the wake of uncertainty at the international level, the dream of single global market for trading carbon permits now seems far-fetched, if not impossible. Indeed, we see a multiplicity of regional, national and even sub-national markets emerging, most 
notably the emissions trading system set up by the European Union (EU ETS) in 2005. The others include, the Regional Greenhouse Gas Initiative (RGGI) in the North Eastern United States, the New Zealand Emissions Trading Scheme, Switzerland Emissions Trading Scheme, Australia Carbon Pricing Mechanism, to name a few.

The EU has created by far the largest market based system to reduce GHG emissions, that is, the European Union Emissions Trading System (EU ETS). This system has operated in phases with the first phase from 2005-2007, wherein modest emission goals were enacted and coverage was restricted to certain sectors. Also, the vast majority of allowances were allocated free of charge in the first and second phase (2008 to 2012), and each nation determined the levels and distribution of allowances to different sectors (Newell et al., 2013). Phase III of the scheme began in 2013, whereby the scope of the scheme was expanded to include Croatia and new sectors and gases.

Laing et al., 2013 concluded that EU ETS drove around 40-80 $\mathrm{MtCO}_{2}$ of annual abatement for phase I and II, or 2-4 per cent of the total capped emissions. However, some of this abatement seemed fictitious, as some projects were non-additional and the abatement brought about by a part of the others was mostly overestimated (Zhang and Wang, 2011). Another matter of contention has been that whether the EU ETS has stimulated long-term green investments and innovation rather than short-term fuel switching and energy conservation (Newell et.al, 2013). Early research into Europe's Emissions Trading System suggested that such long-term investments might be limited (Leiter et al., 2011). However, carbon markets might still be too new to inspire long-term confidence to make these investments (Newell et.al, 2013).

Additionally, the distributional effects of the system have been rather unfair, as prices of allowances have been passed on to the end users resulting in significant windfall profits for sectors receiving free allowances (Branger et al., 2013).However, such experiences have led the Commission to switch to auctioned allocations at the start of phase III with 100 per cent auction for electricity production in utilities (except some transitional free allowances for Eastern European member states to modernize power plants), some free allowances for their heat production and for industrial participants through benchmarking. Further, the system witnessed noteworthy fraud on account of Value Added Tax (VAT), identity thefts by cyber-attacks and recycling of Certified Emission Reduction (CER) offset credits remitted by the Hungarian administration (Branger et al., 2013). Meanwhile, confidence in the EU ETS has been hit hard given its inability to cope with the economic downturn. Prices in the system have remained depressed in the range of about US\$5-9 (€4-7).

There are fears that the EU ETS would exhaust most of its Kyoto credit limit in the next few years, ahead of 2020 deadline. This is in the wake of current low prices and 
spread with the European Union Allowances. Also, there are no plans regarding demand for international credits after the 2020 deadline, under the current EU proposal for 2030 emission reduction targets.

Nevertheless, the system expects to achieve a 40 per cent GHG reduction in the EU as a whole below the 1990 levels and increase the linear annual reduction of their cap. Also, negotiations are in place to link the EU ETS with other emissions trading schemes. The European Commission and Australia announced an agreement in August 2012for linking the EU ETS and Australian emissions trading scheme. Under this arrangement, businesses would be able to use carbon units from the Australian ETS or the EU ETS for compliance under either system. The full two-way link is expected to start in 2018. The Commission is also negotiating with Switzerland on linking EU ETS with the Swiss ETS. These attempts on the part of the European Union are in line with its expectation that an international carbon market would develop whereby participants in one system could use units from a linked system for compliance purposes.

\subsection{Conclusion}

Any discussion on environment would stand incomplete without addressing the menace of global warming, which is caused by accumulation of greenhouse gases (mainly $\mathrm{CO}_{2}$ ) in the atmosphere. The Kyoto Protocol, an initiative to tackle this phenomenon led to the evolution of carbon markets. Carbon trading, a mechanism introduced under the Protocol, enables countries with emissions above a prescribed quota to buy credits from countries with emissions below quota (Gupta, 2011). The Kyoto dream was of a unified global carbon market, which would render a check on the worldwide emission levels. However, with actual experience, this dream seems a little far-fetched, if not impossible. What seems to be emerging is a decentralised, bottom-up carbon market whereby international negotiations would be the key to warrant further progress (Newell et.al, 2013).

There are multiple regional, national and even sub-national markets in operation with the European Union Emissions Trading System (EU-ETS) being the largest. The functioning of these markets has spelt out some key lessons in terms of emissions reductions, effects of free allowance allocations on end users, the phenomenon of carbon leakage, risk associated with high and/or volatile carbon prices, and so on. There have been some unanticipated concerns as well such as those regarding linkage of the multiple carbon markets, revision of government set programs for new information, comparisons between a mix of abatement policy tools (emissions trading, an emissions tax, a performance standard etc.) being contemplated and so on (Newell et.al, 2013). 
Though the international scenario continues to remain uncertain, progress at the regional, national and even sub-national levels continues to show some promise for the future. Eight new carbon markets opened their doors in 2013 alone and there are many others already under consideration. The EU ETS has been leading from the front in creating this tremendous momentum. Also, these systems are starting to link with one another, to enable participants in one system to use units from another for compliance purposes and facilitate the evolution of an international carbon market.

Overall, the literature on emissions trading coupled with the demand-supply outlook for Kyoto credits indicate the emergence of a decentralised bottom-up market design. Moreover, proposals to tackle climate change have entailed some type of border measures as well. Border carbon adjustments (BCA) consist of taxing imports and possibly subsidizing exports according to their carbon content. Though slow progress in negotiations for a global climate agreement increases the prospects for implementation of BCA, the empirical literature devoted to assessment of their environmental impact remains limited (Brandi, 2013).

Although further research is needed especially on the environmental effects of border carbon measures, it could be said that more efforts should be directed towards enactment and implementation of a global climate agreement, which would address central concerns of human development and environmental ethics. However, having said this, the greatest limitation remains that the global environment is generated by virtue of global climate chains, which are often integrated, dynamic and cascading. It therefore becomes impossible to frame policy alternatives to address issues like climate change, $\mathrm{CO}_{2}$ emissions, and so on because the biggest problem is establishing a cause and effect relationship. These phenomena like global warming, ozone layer depletion and $\mathrm{CO}_{2}$ emissions are global phenomena such that the cause may lie in one part of the globe but the effects might be felt elsewhere. So, the major policy implication is that there cannot be any equity in accountability of the environment. While there are some general principles like polluters pay principle but their implementation is a pipe dream.

\section{References}

Brandi, Clara (2013). Trade and climate change: Environmental, economic and ethical perspectives on border carbon adjustments. Ethics, Policy \& Environment, 16(1): 79-93.

Branger, Frédéric et al. (2013). The European Union Emissions Trading System: Should we throw the flagship out with the bathwater?'. Working Paper No. 48, Centre International de Recherches sur I'Environnement et le Développement (CIRED). 
Dinica, Valentina (2002). Energy policies for $\mathrm{CO} 2$ emissions reduction. In Yotova, A. (ed) Natural Resource System Challenge II - Climate Change, Human Systems and Policy, Encyclopedia of Life Support Systems, EOLSS Publishers Co., Oxford: UK.

Goldar, Bishwanath \& Pratap, Devender (2013). Emission reduction commitments and international carbon trading: Assessment of impact on India and China based on GTAPE Model'. Web reference: http://ssrn.com/abstract $=2207651$.

Gupta, Yuvika (2011). Carbon credit: A step towards green environment. Global Journal of Management and Business Research, 11(5): 16-20.

Laing, Tim, Stao, M., Grubb, M., \& Comberti, C. (2013). Assessing the effectiveness of the EU emissions trading system. Working Paper No. 126, Centre for Climate Change Economics and Policy, London School of Economics

Leiter, Andrea M., Paolini, Arno \& Winner, Hannes (2011). Environmental regulation and investment: Evidence from European industry data. Ecological Economics,70(4): 759-770.

Lo, Alex Y. (2013). Carbon trading in a socialist market economy: Can China make a difference? Ecological Economics, 87: 72-74.

Newell, Richard G., Pizer, William A., \& Raimi, Daniel (2013). Carbon markets 15 years after Kyoto: Lessons learned, new challenges. Journal of Economic Perspectives, 27(1): 123-146.

World Bank (2014). State and Trends of Carbon Pricing, World Bank, May. Washington DC,

Zhang, Junjie \& Wang, Can (2011). Co-benefits and additionality of the clean development mechanism: An empirical analysis. Journal of Environmental Economics and Management, 62(2): 140-154. 